\title{
Editorial: Emerging and Re-emerging Vector-borne and Zoonotic Diseases
}

\author{
Alfonso J. Rodriguez-Morales ${ }^{1,2,3,4 *}$, Jaime A. Cardona-Ospina ${ }^{1,2}$ and Matthew H. Collins ${ }^{5}$ \\ ${ }^{1}$ Grupo de Investigación Biomedicina, Faculty of Medicine, Fundacion Universitaria Autonoma de las Americas, Pereira, \\ Colombia, ${ }^{2}$ Emerging Infectious Diseases and Tropical Medicine Research Group, Instituto para la Investigación en Ciencias \\ Biomédicas - Sci-Help, Pereira, Colombia, ${ }^{3}$ School of Medicine, Universidad Privada Franz Tamayo (UNIFRANZ), \\ Cochabamba, Bolivia, ${ }^{4}$ Faculty of Health Sciences, Universidad Cientifica del Sur, Lima, Peru, ${ }^{5}$ Division of Infectious \\ Diseases, Department of Medicine, Emory University School of Medicine, Atlanta, GA, United States
}

Keywords: vector-borne diseases, zoonotic diseases, emerging, tropical diseases, emerging infectious diseases, global health, spillover, pandemic

\section{Editorial on the Research Topic}

\section{Emerging and Re-emerging Vector-borne and Zoonotic Diseases}

The Colombian Nobel laureate Gabriel Garcia Marquez stated in his last will, "la muerte no llega con la vejez, sino con el olvido" ("death does not come with old age, but with oblivion"). Indeed, how many deaths due to tropical diseases can be avoided? How can investment in these neglected diseases significantly change the course of the disease? Even in a macro vision, how could the socioeconomic condition of those affected by these diseases be changed to avoid transmission, morbidity, and mortality? We must rescue tropical and emerging global diseases from oblivion, and the rescue begins with us.

Despite significant advances in diagnostic tools, sequencing technologies (1-5), new drugs, and vaccine development using precision medicine (6-9), pharmacogenomics (10-12), computational and in silico models (13-16), and artificial intelligence (17-20); the benefits of these accomplishments have not been fully realized in the field of emerging and re-emerging vector-borne and zoonotic diseases (21). Emerging vector-borne and zoonotic diseases are a growing threat to global health and have caused hundreds of billions of US dollars of economic damage in the past 20 years (22). Together, these infections are responsible for a substantial disease burden, with endemic and enzootic zoonoses, and metaxenic diseases causing about a billion cases of illness in people and millions of deaths every year (22). Moreover, old foes with us for hundreds [like Chagas disease (23-25)] or thousands [like leprosy or Hansen's disease (26-28)] of years are yet to be eliminated or controlled in many countries. This is the tragedy of neglected tropical diseases. Disinterest and disincentive are monstrous impediments to the progress that could be made by governments, major pharmaceutical companies, and other actors in the development of new drugs, research initiatives, diagnostics, and vaccines for these diseases.

The rescue from oblivion is accomplished in multiple ways, including increasing visibility; generating, disseminating, and implementing new knowledge and evidence; elaborating strategies and tools for the benefit of communities and patients, and pursuing research in a more integrated and comprehensive form, but also looking for ways to translate that research into policies. After millennia, standing in the dawn of the XXI century, we are at a crossroads. We can reinvigorate the global commitment to confront these problems; otherwise, several of these conditions will persist, taking millions of lives, causing substantial disability, and increasing poverty in already impoverished populations.

This collection of articles endeavors to identify unique and essential challenges and opportunities for improving the management of vector-borne and zoonotic diseases. As 
clinician-investigators, we favor a future that is characterized by improved health metrics globally and a human population that seeks to be a good steward of the planet on which it depends. Of course, it is easy to pontificate about what must be done and how grand the scale should be. However, viable solutions will accept the arduous tasks that buttress their pursuit. Our world is one of limited capital (political, human, financial). Thus, the field of vector-borne and zoonotic diseases needs to include advocates, educators, and communicators to ensure that populations have awareness and understanding of what is at stake for their future and political leaders are held accountable to serve the best interest of their people through policy and resource allocation (29-31). Here, we outline vital ideas that will shape the future of the vector-borne and zoonotic diseases field. We draw on One Health and Planetary Health models-essentially recognizing the interdependence of human health, animal health, and environmental health; ideas endorsed by major international organizations such as WHO (32) - and include lessons learned from the contributors to this collection of articles.

The diagnostics underlying surveillance are a cornerstone for the public health management of infectious diseases, providing a means to monitor and model transmission and evaluate the impact of prevention and control activities (33). However, existing systems vary considerably in the organization, investment, and linkage to action or resource mobilization. Surveillance networks often focus on a specific pathogen but may also be centered on the syndromic presentation of illnesses such as acute respiratory illness or hemorrhagic fever. While serologic approaches remain important, molecular surveillance is the nexus of pathogen discovery and monitoring. Global surveillance must be strengthened at all levels. Bolstering existing vertical systems at local and national levels has advantages. These include investment in training and deployment of skilled field epidemiologists and maintenance of information systems for collecting, analyzing, and reporting data. Complimentary efforts by international entities such as the WHO to standardize practices and definitions help coordinate response efforts. Given the high volume of (pre-2020) international travel, unique surveillance networks that precisely monitor travelrelated infections offer exciting opportunities to assess the spread of infectious diseases across borders (34-36). Of course, case definitions must be in place and diagnostic tools must be rapidly developed and deployed for novel pathogens to enable accurate surveillance. Making surveillance information robust and readily accessible accelerates research to understand and respond to existing and novel pathogens while informing public health decisions.

Treatment and prevention of infections are critical. Vaccination, which is not covered further here due to space limitations, is among the most celebrated achievements in medicine, and recent efforts in the Zika and COVID-19 pandemics have set an incredibly high bar for the rapidity with which safe and effective vaccine candidates can be developed (37). There are no licensed antivirals and a dearth of promising candidates for emerging diseases such as SARS, MERS, Ebola and Zika (38). The trend has been that intense research and publications follow on the heels of news of a new epidemic of potential global concern. However, interest and investment in these activities quickly subside. A greater armamentarium of treatments could have enormous benefits for combatting future vector-borne and zoonotic diseases, which is precisely the goal of innovative initiatives such as READDI (Rapidly Emerging Antiviral Drug Discovery Initiative) (38). Completing phase 1 trials of antivirals does not require a pre-known indication. We could start at phase 2, quickly screen in vitro, and test in vivo in parallel.

This Research Topic by Frontiers in Medicine and Frontiers in Public Health brings together a diversity of articles that focus on different pathogens, representing different points on the translational research spectrum, anchored in different disciplines. The goal was to provide a succinct sample of the vector-borne and zoonotic diseases affecting populations worldwide and some of the scientific methods involved in a public health response. The collection was finalized in 2019; but, the events of 2020 cannot be ignored. The COVID-19 pandemic is nothing less than a calamity. However, the emergence of SARS-CoV-2 is neither unique nor surprising; it is part of a pattern and process, and the palpable consequence of the close correlation of human, environmental, and animal health. Details of emergence are difficult to predict, but the reality that our global ecosystem holds countless potential pathogens, particularly RNA viruses, that could "spillover" under certain conditions and propagate among humans is well-known. The possible emergence of other $\mathrm{CoV}$ epidemics was predicted in the prescient work by Menachery et al., several years before the current pandemic (39). The COVID19 pandemic has been difficult and tragic, but it also reveals the need for dedicated attention to comprehensive management plans for vector-borne and zoonotic diseases that could prevent future catastrophes.

This Research Topic has exceeded expectations in scope and content. The original article on dengue is an exciting paper, combining findings and experiences from two endemic countries in Latin America (Ecuador) and Asia (Thailand) Anderson et al. The Zika virus papers show the importance of surveillance and the broad spectrum of congenital disorders associated with this arbovirus, as is the case of arthrogryposis Contreras-Capetillo et al. and Lim et al. In addition to the epidemiological and clinical aspects of arboviruses, basic immunological aspects are also crucial in understanding these conditions, as shown in the article about $\mathrm{T}$ cell responses to Japanese encephalitis Pushpakumara et al. After the 2014 epidemics, Ebola persisted in countries such as the Democratic Republic of Congo, representing a significant burden of morbidity and mortality, as discussed in the article by Grimes et al. Myiasis, although forgotten by many, is still causing problems in different populations, including newborns, as discussed in the article by Ruiz-Zapata et al. The role of dogs in multiple zoonotic diseases still needs to be addressed regarding multiple pathogens, including Echinococcus granulosus, as presented by Khan et al., in their article. Coinfections represent a challenge in the context of tropical diseases related to other tropical diseases, but also other infectious diseases; this interesting aspect in the context of HIV is presented in the diagnosis of visceral leishmaniasis da Silva et al. In its vision of ecoepidemiology, the article of Krystosik 
on the role of solid waste in breeding sites, burrows, and food for vectors and urban zoonotic reservoirs is fascinating Krystosik et al.

It seems clear that zoonotic and emerging infectious diseases must be confronted via a multifaceted approach, which includes integrating across disciplines (veterinary medicine, vector biology, immunology, epidemiology, among others) as well as across biological scales (molecules $\rightarrow$ pathogens $\rightarrow$ ecosystems). Among the best existing frameworks to improve integration in our concepts, health offers new collaborations and actions. We will undoubtedly be given additional opportunities to react to small outbreaks or new pandemic threats (32, 40-43). However, success in this field will be marked by an increasingly proactive and preemptive mode of operation-we need to know what is coming, have adequate tools and therapeutics poised for application and adaptation, and identify measures to prevent the emergence of novel pathogens (rather than the spread of

\section{REFERENCES}

1. Chen X, Kang Y, Luo J, Pang K, Xu X, Wu J, et al. Next-generation sequencing reveals the progression of COVID-19. Front Cell Infect Microbiol. (2021) 11:632490. doi: 10.3389/fcimb.2021.632490

2. Sehli S, Allali I, Chahboune R, Bakri Y, Al Idrissi N, Hamdi $\mathrm{S}$, et al. Metagenomics approaches to investigate the gut microbiome of COVID-19 patients. Bioinform Biol Insights. (2021) 15:1177932221999428. doi: 10.1177/1177932221999428

3. Zhang X, Wu Z, Wang K. Diagnosis of Streptococcus suis Meningoencephalitis with metagenomic next-generation sequencing of the cerebrospinal fluid: a case report with literature review. BMC Infect Dis. (2020) 20:884. doi: 10.1186/s12879-020-05621-3

4. Callanan J, Stockdale SR, Shkoporov A, Draper LA, Ross RP, Hill C. Biases in viral metagenomics-based detection, cataloguing and quantification of bacteriophage genomes in human faeces, a review. Microorganisms. (2021) 9:524. doi: 10.3390/microorganisms9030524

5. Avila-Rios S, Parkin N, Swanstrom R, Paredes R, Shafer R, Ji H, et al. Next-generation sequencing for HIV drug resistance testing: laboratory, clinical, and implementation considerations. Viruses. (2020) 12:617. doi: $10.3390 / \mathrm{v} 12060617$

6. Martins Dos Santos VAP, Hardt C, Skrede S, Saccenti E. Systems and precision medicine in necrotizing soft tissue infections. Adv Exp Med Biol. (2020) 1294:187-207. doi: 10.1007/978-3-030-57616-5_12

7. Merker M, Tueffers L, Vallier M, Groth EE, Sonnenkalb L, Unterweger D, et al. Evolutionary approaches to combat antibiotic resistance: opportunities and challenges for precision medicine. Front Immunol. (2020) 11:1938. doi: 10.3389/fimmu.2020.01938

8. Rossi JF, Lu ZY, Massart C, Levon K. Dynamic immune/inflammation precision medicine: the good and the bad inflammation in infection and cancer. Front Immunol. (2021) 12:595722. doi: 10.3389/fimmu.2021.595722

9. Keij FM, Achten NB, Tramper-Stranders GA, Allegaert K, van Rossum AMC, Reiss IKM, et al. Stratified management for bacterial infections in late preterm and term neonates: current strategies and future opportunities toward precision medicine. Front Pediatr. (2021) 9:590969. doi: 10.3389/fped.2021.590969

10. Stocco G, Lucafo M, Decorti G. Pharmacogenomics of antibiotics. Int J Mol Sci. (2020) 21:5975. doi: 10.3390/ijms21175975

11. Takahashi T, Luzum JA, Nicol MR, Jacobson PA. Pharmacogenomics of COVID-19 therapies. NPJ Genom Med. (2020) 5:35. doi: 10.1038/s41525-020-00143-y

12. Al-Eitan LN, Alahmad SZ. Pharmacogenomics of genetic polymorphism within the genes responsible for SARS-CoV-2 susceptibility and the drug-metabolising genes used in treatment. Rev Med Virol. (2021) 31:e2194. doi: 10.1002/rmv.2194 emerging diseases) - particularly as a counter to myopic or destructive human activity, as these are a detrimental driver for the health of our species.

Many are hard at work, but more effort is required and the challenges are great. We want a world with equity, less disease, and more health, especially in those areas where the impact of these conditions has truncated the lives of millions. We hope readers will benefit from the insights of the experiences and findings in this Research Topic whilst also being motivated to take action in pulling these diseases, and those who suffer from them, out of oblivion.

\section{AUTHOR CONTRIBUTIONS}

All authors contributed to manuscript conception and design, literature review, manuscript preparation, critical review, and contributed to the article and approved the submitted version.

13. Borba J, Silva AC, Lima MNN, Mendonca SS, Furnham N, Costa FTM, et al. Chemogenomics and bioinformatics approaches for prioritizing kinases as drug targets for neglected tropical diseases. Adv Protein Chem Struct Biol. (2021) 124:187-223. doi: 10.1016/bs.apcsb.2020.10.006

14. Dariolli R, Campana C, Gutierrez A, Sobie EA. In vitro and in silico models to study SARS-CoV-2 infection: integrating experimental and computational tools to mimic "COVID-19 Cardiomyocyte". Front Physiol. (2021) 12:624185. doi: 10.3389/fphys.2021.624185

15. Kinobe RT, Owens L. A systematic review of experimental evidence for antiviral effects of ivermectin and an in silico analysis of ivermectin's possible mode of action against SARS-CoV-2. Fundam Clin Pharmacol. (2021) 35:26076. doi: $10.1111 / \mathrm{fcp} .12644$

16. Mottaqi MS, Mohammadipanah F, Sajedi H. Contribution of machine learning approaches in response to SARS-CoV-2 infection. Inform Med Unlocked. (2021) 23:100526. doi: 10.1016/j.imu.2021.100526

17. Rasheed J, Jamil A, Hameed AA, Aftab U, Aftab J, Shah SA, et al. A survey on artificial intelligence approaches in supporting frontline workers and decision makers for the COVID-19 pandemic. Chaos Solitons Fractals. (2020) 141:110337. doi: 10.1016/j.chaos.2020.110337

18. Rosa V, Ho D, Sabino-Silva R, Siqueira WL, Silikas N. Fighting viruses with materials science: prospects for antivirus surfaces, drug delivery systems and artificial intelligence. Dent Mater. (2021) 37:496-507. doi: 10.1016/j.dental.2020.12.004

19. Alsharif MH, Alsharif YH, Albreem MA, Jahid A, Solyman AAA, Yahya $\mathrm{K}$, et al. Application of machine intelligence technology in the detection of vaccines and medicines for SARS-CoV-2. Eur Rev Med Pharmacol Sci. (2020) 24:11977-81. doi: 10.26355/eurrev_202011_23860

20. Yoganandhan A, Rajesh Kanna G, Subhash SD, Hebinson Jothi J. Retrospective and prospective application of robots and artificial intelligence in global pandemic and epidemic diseases. Vacunas. (2021) 22:98105. doi: 10.1016/j.vacun.2020.12.004

21. Rodriguez-Morales AJ, Paniz-Mondolfi AE, Faccini-Martínez ÁA, HenaoMartínez AF, Ruiz-Saenz J, Martinez-Gutierrez M, et al. The constant threat of zoonotic and vector-borne emerging tropical diseases: living on the edge. Front Trop Dis. (2021) 2:676905. doi: 10.3389/fitd.2021. 676905

22. Karesh WB, Dobson A, Lloyd-Smith JO, Lubroth J, Dixon MA, Bennett M, et al. Ecology of zoonoses: natural and unnatural histories. Lancet. (2012) 380:1936-45. doi: 10.1016/S0140-6736(12)61678-X

23. Morel CM. Chagas disease, from discovery to control - and beyond: history, myths and lessons to take home. Mem Inst Oswaldo Cruz. (1999) 94(Suppl. 1):3-16. doi: 10.1590/S0074-02761999000700002

24. Von A, Zaragoza E, Jones D, Rodriguez-Morales AJ, Franco-Paredes C. New insights into Chagas disease: a neglected disease in Latin America. J Infect Dev Ctries. (2007) 1:99-111. 
25. Franco-Paredes C, Von A, Hidron A, Rodriguez-Morales AJ, Tellez I, Barragan M, et al. Chagas disease: an impediment in achieving the Millennium Development Goals in Latin America. BMC Int Health Hum Rights. (2007) 7:7. doi: 10.1186/1472-698X-7-7

26. Franco-Paredes C, Rodriguez-Morales AJ. Unsolved matters in leprosy: a descriptive review and call for further research. Ann Clin Microbiol Antimicrob. (2016) 15:33. doi: 10.1186/s12941-016-0149-x

27. Franco-Paredes C, Marcos LA, Henao-Martinez AF, Rodriguez-Morales AJ, Villamil-Gomez WE, Gotuzzo E, et al. Cutaneous mycobacterial infections. Clin Microbiol Rev. (2018) 32:e0069-18. doi: 10.1128/CMR.00069-18

28. Hensler PG. Analysis of an important work, published a few years since in Denmark, and hitherto unknown in England, on the leprosy of the west in the middle ages, with a supplement relating to the history and knowledge of the disease. Med Phys J. (1803) 9:554-66.

29. Hess J, Boodram LG, Paz S, Stewart Ibarra AM, Wasserheit JN, Lowe R. Strengthening the global response to climate change and infectious disease threats. BMJ. (2020) 371:m3081. doi: 10.1136/bmj.m3081

30. Sands P, Mundaca-Shah C, Dzau VJ. The neglected dimension of global security-a framework for countering infectious-disease crises. $N$ Engl J Med. (2016) 374:1281-7. doi: 10.1056/NEJMsr1600236

31. Zismer DK, Werner MJ. Managing the physics of the economics of integrated health care. Physician Exec. (2012) 38:38-45.

32. Emerging zoonoses: a one health challenge. EClinicalMedicine. (2020). 19:100300. doi: 10.1016/j.eclinm.2020.100300.

33. Martinez L. Global infectious disease surveillance. Int $J$ Infect Dis. (2000) 4:222-8. doi: 10.1016/S1201-9712(00)90 114-0

34. Freedman DO, Kozarsky PE, Weld LH, Cetron MS. GeoSentinel: the global emerging infections sentinel network of the International Society of Travel Medicine. J Travel Med. (1999) 6:94-8. doi: 10.1111/j.1708-8305.1999.tb00 839.x

35. Gallego V, Berberian G, Lloveras S, Verbanaz S, Chaves TS, Orduna $\mathrm{T}$, et al. The 2014. FIFA World Cup: communicable disease risks and advice for visitors to Brazil-a review from the Latin American Society for Travel Medicine (SLAMVI). Travel Med Infect Dis. (2014) 12:208-18. doi: 10.1016/j.tmaid.2014.0 4.004

36. Gallego V, Berberian G, Siu H, Verbanaz S, Rodriguez-Morales AJ, Gautret P, et al. The 2019 Pan American games: communicable disease risks and travel medicine advice for visitors to Peru - Recommendations from the Latin American Society for Travel Medicine (SLAMVI). Travel Med Infect Dis. (2019) 30:19-24. doi: 10.1016/j.tmaid.2019.06.011
37. Ball $P$. The lightning-fast quest for COVID vaccines - and what it means for other diseases. Nature. (2021) 589:16-8. doi: 10.1038/d41586-020-03626-1

38. Bobrowski T, Melo-Filho CC, Korn D, Alves VM, Popov KI, Auerbach S, et al. Learning from history: do not flatten the curve of antiviral research! Drug Discov Today. (2020). 25:1604-13. doi: 10.1016/j.drudis.2020.07.008

39. Menachery VD, Yount BL, Jr., Debbink K, Agnihothram S, Gralinski LE, et al. A SARS-like cluster of circulating bat coronaviruses shows potential for human emergence. Nat Med. (2015) 21:1508-13. doi: 10.1038/nm.3985

40. Scott J. Proposed integrated control of zoonotic plasmodium knowlesi in southeast asia using themes of one health. Trop Med Infect Dis. (2020) 5:175. doi: 10.3390/tropicalmed5040175

41. Bonilla-Aldana DK, Holguin-Rivera Y, Perez-Vargas S, Trejos-Mendoza AE, Balbin-Ramon GJ, Dhama K, et al. Importance of the One Health approach to study the SARS-CoV-2 in Latin America. One Health. (2020) 10:100147. doi: 10.1016/j.onehlt.2020.100147

42. Rodriguez-Morales AJ, Patino-Cadavid LJ, Lozada-Riascos CO, VillamilGomez WE. Mapping Zika in municipalities of one coastal department of Colombia (Sucre) using geographic information systems during the 20152016 outbreak: implications for public health and travel advice. Int J Infect Dis. (2016) 48:70-2. doi: 10.1016/j.ijid.2016.05.012

43. Rodriguez-Morales AJ, Schlagenhauf P. Zoonoses and travel medicine: "one world-one health". Travel Med Infect Dis. (2014) 12:555-6. doi: 10.1016/j.tmaid.2014.11.003

Conflict of Interest: The authors declare that the research was conducted in the absence of any commercial or financial relationships that could be construed as a potential conflict of interest.

Publisher's Note: All claims expressed in this article are solely those of the authors and do not necessarily represent those of their affiliated organizations, or those of the publisher, the editors and the reviewers. Any product that may be evaluated in this article, or claim that may be made by its manufacturer, is not guaranteed or endorsed by the publisher.

Copyright (c) 2021 Rodriguez-Morales, Cardona-Ospina and Collins. This is an open-access article distributed under the terms of the Creative Commons Attribution License (CC BY). The use, distribution or reproduction in other forums is permitted, provided the original author(s) and the copyright owner(s) are credited and that the original publication in this journal is cited, in accordance with accepted academic practice. No use, distribution or reproduction is permitted which does not comply with these terms. 